\title{
Chronic stiff, aching left foot
}

Thomas Bean $^{1}$ - Asif Saifuddin ${ }^{2}$

Published online: 17 July 2017

(C) ISS 2017

\section{History}

Thirty-six year-old carpenter with left foot pain and stiffness Figure 1. (Sagittal PD), Figs. 2 and 3 (axial PD), and Fig. 4 (sagittal STIR).

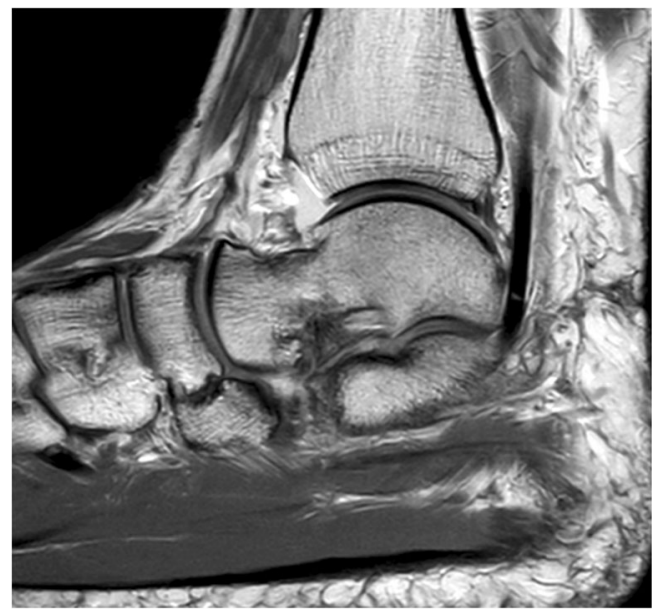

Fig. 1 Sagittal PD-weighted MRI

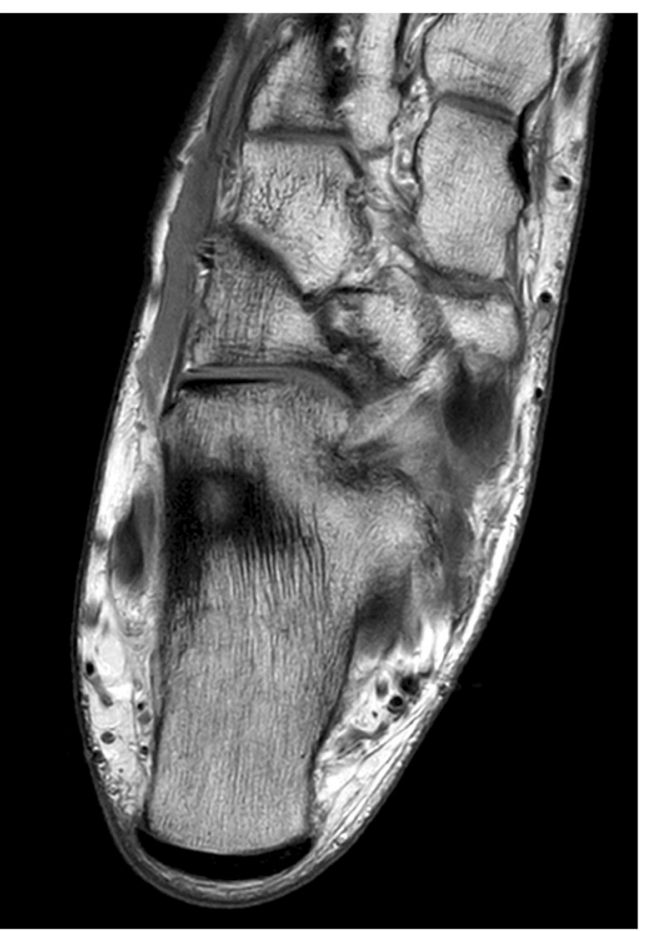

Fig. 2 Axial PD-weighted MRI

The diagnosis can be found at doi: 10.1007/s00256-017-2720-8

$\triangle$ Thomas Bean

t.bean@nhs.net

1 Derriford Hospitals NHS Trust, Plymouth, UK

2 Royal National Orthopaedic Hospital NHS Trust, Stanmore, UK 

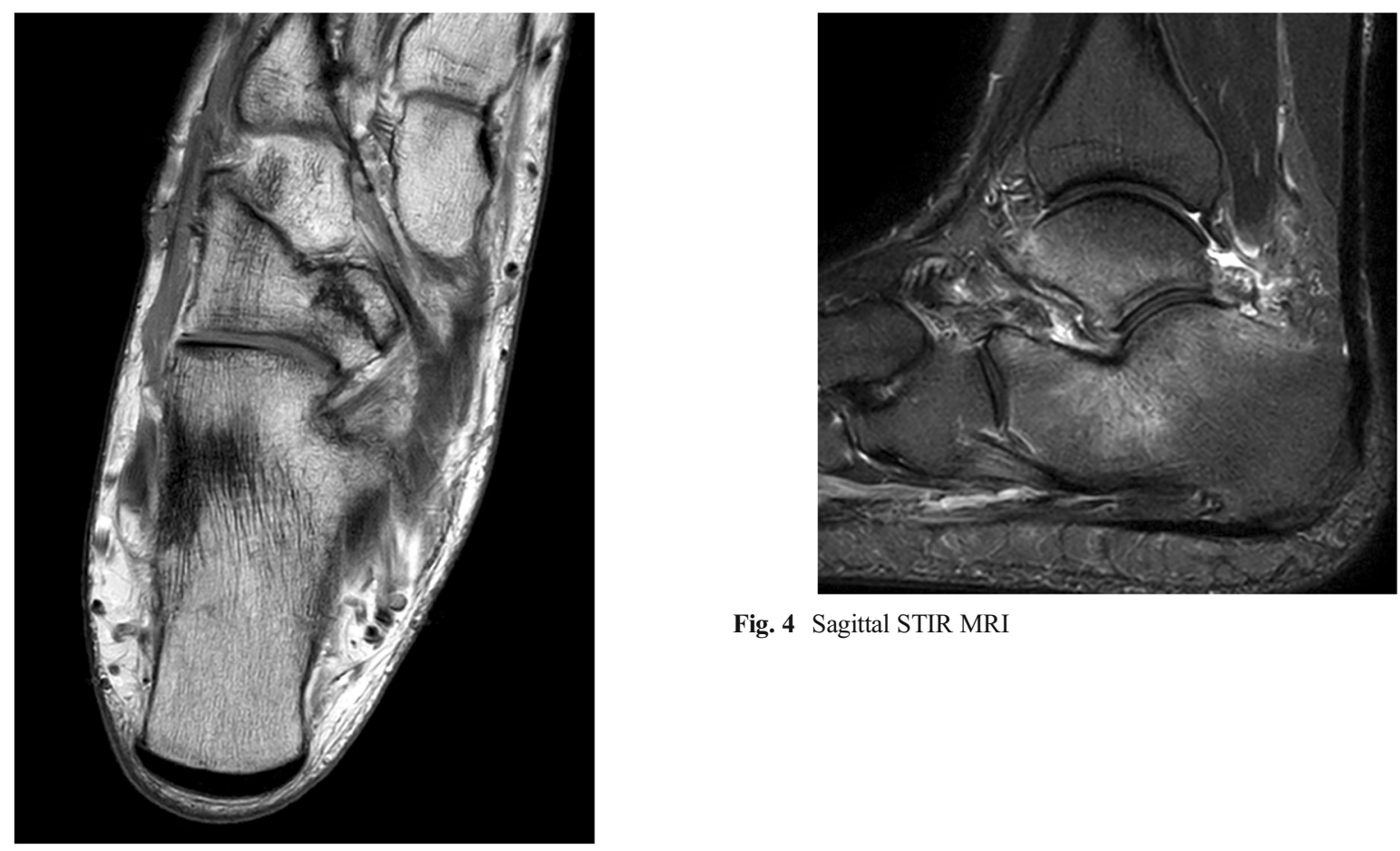

Fig. 4 Sagittal STIR MRI

Fig. 3 Axial PD-weighted MRI 